\title{
Effect of Curing Temperature on Mechanical Properties of Bio-Phenolic/Epoxy Polymer Blends
}

\author{
Ahmad Safwan Ismail \\ Universiti Putra Malaysia \\ Norul Hisham Hamid \\ Universiti Putra Malaysia \\ Ridwan Yahaya \\ STRIDE

\section{Azman Hassan \\ Universiti Teknologi Malaysia \\ Mohammad Asim \\ Universiti Putra Malaysia}

\section{A.B.M. Supian \\ Universiti Putra Malaysia}

Mohammad Jawaid ( $\nabla$ jawaid_md@yahoo.co.in )

Universiti Putra Malaysia https://orcid.org/0000-0001-5348-5740

\section{Research Article}

Keywords: Epoxy, Bio-phenolic, Polymer blends, Tensile properties, Flexural properties

Posted Date: May 14th, 2021

DOI: https://doi.org/10.21203/rs.3.rs-463534/v1

License: (c) (i) This work is licensed under a Creative Commons Attribution 4.0 International License.

Read Full License

Version of Record: A version of this preprint was published at Journal of Polymers and the Environment on July 22nd, 2021. See the published version at https://doi.org/10.1007/s10924-021-02244-w. 


\section{Abstract}

Nowadays, researchers continue studies for alternative materials to replace the redundant petroleumbased products. The combination of various polymer mixture process mainly from bio-polymer material as a matrix property could reduce the dependence over petroleum-based polymer, thus the dangerous residue waste from the synthetic polymer in the fabrication process could be eliminated and produce better composite material with lower cost and high performance of composite material in numerous applications. In this study, the effect of bio-phenolic loading and curing temperature on the mechanical properties of bio-phenolic/epoxy polymer blends was investigated. Bio-phenolic/epoxy polymer blends were fabricated with different loading of bio-phenolic resin (5(P-5), 10(P-10), 15(P-15), 20(P-20) and 25(P25) wt\%) and different curing temperature was used which is $100^{\circ} \mathrm{C}, 130{ }^{\circ} \mathrm{C}$ and $150{ }^{\circ} \mathrm{C}$. The overall mechanical properties of bio-phenolic/epoxy polymer blends were improved as bio-phenolic loading increase and curing temperature increase. Based on the analysis, bio-phenolic/epoxy polymer blends with 20 wt \% bio-phenolic showed the best overall mechanical properties. Besides that, $150{ }^{\circ} \mathrm{C}$ curing temperature was the most suitable curing temperature for bio-phenolic/epoxy polymer blends based on the overall mechanical properties.

\section{Introduction}

The phenolic resins were the first fully synthetic resins has exploited, and the first polymeric materials produced commercially from basic low molecular weight compounds [1]. Phenolic resin is also has known as a polymer that has been used in many applications, for instance, coating, adhesive, composites wood materials, laminates, paper, and natural fiber composites [2]. Besides that, phenolic resin was favourable economics and have excellent properties of high thermal stability and nonflammability features which are fit for interior application and other components in the automotive, aerospace and marine transportation industries [2-5] Meanwhile, biomass is the world's most viable source of organic carbon, providing about $14 \%$ of the world's energy needs and also serving as a source of biofuels and valuable chemical compounds, besides, the use of biomass in bio-phenolic resin could sustain the resources of raw material, a green energy source with a $\mathrm{CO}_{2}$ neutral global balance, and its use for energy has recently sparked a lot of interest around the world $[6,7]$

Compared to phenolic resin, epoxy has better mechanical properties. Therefore, it has been used widely in many applications including high performance composites materials and the most frequent thermoset polymer in aircraft structures application [8]. Because of their good mechanical properties, low cost, high specific strength, good heat and solvent tolerance, and super adhesiveness, therefore epoxy-based composite materials are commonly used in load-bearing applications, such as automotive, aerospace, building, oil and gas, and marine industries. Moreover, the value of the cured resin, which includes good adhesion to many substrates, relatively high durability (especially when rubber modified), high electrical resistivity, good environmental resistance, low shrinkage, and so on, as well as the ease with which the curing reaction can be tailored to accommodate the fabricating process and others industrial demand $[9,10]$ 
However, the drawback of using phenolic is brittleness and shrinkage, thus, not suitable to be used in advanced engineering areas $[2,11]$ Meanwhile, the phenol and formaldehyde (PF) resin is very costly due to the high and fluctuating price of petroleum-based phenol and it has been a considerable push factor in recent decades to replace the raw materials phenol and formaldehyde in the synthetic phase to other renewable bio-based raw materials [7]. Furthermore, the primary source of raw materials for industrial phenol and formaldehyde processing is currently sourcing from petroleum-based material, thus, the various effort has been made to reduce phenol's reliance on petroleum-based due to the massive amounts emitted per year, the decline of fossil fuels, and the environmental issues connected with the use of fossil resources [1,12-14] Otherwise, epoxy has poor thermal and flammability properties compared to phenolic resin, despite it has high mechanical properties, hence, is not suitable to be used in applications that involve heat and flame. Epoxy-based composites are structurally versatile materials that may fulfill the requirements of many applications, but they suffer from insufficient fire resistance and thus the addition of flame retardants (FRs) is often necessary [15].

Numerous study has been exposed on the effect of polymer blend on varies polymer blends process, two or more polymer combination such as thermoplastic-thermoplastic blends, thermoplastic-thermosetting blends, thermoplastic-rubber blends, rubber-thermosetting blends, and polymer-filler blends are the five major categories of polymer blends has extensively studied and generate unique properties into a single system material [16-18]. Besides, the properties of a heterogeneous polymer blend, in general, are determined by the consistency of the polymer phases, while the polymer blend will be miscible if there are strong interactions between the phases [19-21] Asyadi et al. [3] have study on thermoplastic polymer blends which the blends between acrylonitrile butadiene styrene (ABS) and polycarbonate (PC). The distinctive ratios of $A B S$ to $P C(30: 70,40: 60,50: 50)$ were used and it was concluded that blends with a ratio of 30:70 (ABS: PC) are the optimum formulation. Meanwhile, the study on polymer blend of thermoset with thermoset polymer was conducted by Rohde et al. [22] have described that the polymer blend study of epoxy and polydicyclopentadiene has improved the fracture toughness while maintaining the tensile strength modulus of the composite.

Besides, polymer blend studies of polyvinyl butyral with epoxy was studied by Sultan et al. [23], has shown the results of 40:60 (epoxy: polyvinyl butyral) composition in different weight ratio, curing time and curing temperature $\left(30 \mathrm{~min}\right.$ and $\left.160^{\circ} \mathrm{C}\right)$ was the ideal formulation in polymer blend of epoxy and polyvinyl butyral. Otherwise, the study by Hiremath et al. [24] on the effect of varying post-curing temperature of epoxy/alumina polymer has indicated the post-curing at a temperature below the glass transition temperature of epoxy increased the viscoelastic and flexural properties of PNCs, while postcuring at a temperature above the glass transition temperature of epoxy damaged the properties of both neat epoxy and nanocomposites. Meanwhile, Zareanshahraki et al. [25] have indicated the developed UVCurable acrylate-siloxane blends showed promising stability and transparency due to the benefits of curing with radiation and polymer mixing. The combination of polymer blends is the cheapest way to produce new material compared to polymer synthesis and it will produce a new combination of material with improved properties and morphologies. Besides that, polymer blends have other advantages such as better processability, tailor ability to specific needed, quick formulation changes, reduced number of 
grades need to manufacture and stored, and recyclability of blends achieved by control of morphology [26]. Consequently, the production of phenolic compounds from non-petroleum sources such as biophenolic resin has been determined in this present study.

Thus, in this present study, the bio-phenolic resin was prepared in the laboratory by the response of phenol and formaldehyde with the presence of a catalyst. Different weight percent parameters of epoxy were used which are $5,10,15,20,30$ and $40 \mathrm{wt} \%$. Moreover, four types of phenolic resin were synthesized which phenol novolac resin and substitute phenol (t-butyl, phenol, p-cresol and cardanol). To utilize the advantages of both polymers, the polymer blends of phenolic/epoxy with distinct weight percent of phenolic was added in epoxy resin $(2.5,5,10,15$ and $20 \mathrm{wt} \%)$ where this mixture will improve the combinations of novolac resin properties. Therefore, the result in this study has expected that the combination of bio-phenolic resin with epoxy resin will improve mechanical properties with the effect of curing temperature parameter.

\section{Materials And Methods}

\subsection{Material}

The bio-phenolic resin was procured from Chemovate Girinagar, Banglore, India. D.E.R * 331 epoxy resin and epoxy hardener jointmine 905-3S was supplied by Tazdiq Engineering Sdn. Bhd., Malaysia. Teflon sheet was obtained from Evergreen Sdn. Bhd., Malaysia (Fig. 1).

\subsection{Fabrication of Composites}

The bio-phenolic resin was mixed with epoxy resin and stirred using a mechanical stirrer for about 10 minutes until all powder was evenly circulated in the epoxy. The mixed ratio of epoxy/hardener was 2:1, where the process of mixing was using a mechanical stirrer machine and the stirring process was 2 - 4 minutes under room temperature condition. Afterward, the mixing of epoxy/hardener was poured into a designated stainless-steel mold. Teflon sheets were put between mold and steel plate. The mixture was poured into the stainless-steel mold with dimension $150 \mathrm{~mm} \times 150 \mathrm{~mm} \times 3 \mathrm{~mm}$ and placed in the hot press for 15 minutes at temperature of $100^{\circ} \mathrm{C}$. The composite was removed from the mold after 10 minutes cooled down. The formulation of fabrications is shown in Table 1. The experiment was repeated using different curing temperature which is $130^{\circ} \mathrm{C}$ and $150{ }^{\circ} \mathrm{C}$. The prepared samples were shown in Fig. 2 .

\subsection{Experiment}

\subsubsection{Tensile properties}

Tensile test was conducted as per ASTM D-3039 using a $30 \mathrm{kN}$ Bluehill INSTRON 5567 universal testing machine. The samples with measurement $120 \mathrm{~mm} \times 20 \mathrm{~mm} \times 3 \mathrm{~mm}$ were cut using bandsaw JETMAC JMWBS-14. The testing speed used was $2 \mathrm{~mm} / \mathrm{min}$ and $60 \mathrm{~mm}$ gauge length were used. The sample was 
placed in $23 \pm 3{ }^{\circ} \mathrm{C}$ condition chamber at $50 \pm 10 \%$ of relative humidity condition for 24 hours. Each formulation has tested with five replications specimens and was presented in average value.

\subsubsection{Flexural properties}

Flexural test was conducted as per ASTM D-790 using a 30 kN Bluehill INSTRON 5567 universal testing machine. Each specimen was cut using bandsaw JETMAC JMWBS-14 with dimension $127 \mathrm{~mm} \times 12.7$ $\mathrm{mm} \times 3 \mathrm{~mm}$. The support span used was 16 times the depth of the sample and the crosshead speed used was analyzed using Eq. 1. Therefore, for this experiment, five sample replicates were tested where the sample was placed in $23 \pm 3^{\circ} \mathrm{C}$ condition chamber at $50 \pm 10 \%$ of relative humidity condition for 24 hours.

\section{See formula 1 in the supplementary files.}

where:

$\mathrm{R}=$ rate of crosshead motion, $\mathrm{mm} / \mathrm{min}$,

$\mathrm{L}=$ support span, $\mathrm{mm}$,

$\mathrm{d}=$ depth of beam, $\mathrm{mm}$

\subsubsection{Impact properties}

Impact test was conducted as per ASTM D 256 using a Ray Ran advanced universal pendulum impact tester (RR/IMT) (Nuneaton, UK) The samples were cut using a band saw JETMAC JMWBS-14 with dimension $63.5 \mathrm{~mm} \times 12.7 \mathrm{~mm} \times 3 \mathrm{~mm}$. Each formulation has tested with five replications specimens and was presented in average value.

\section{Results And Discussion}

\subsection{Tensile strength}

The effect of curing temperature on the tensile strength of bio-phenolic/epoxy polymer blends with different bio-phenolic loading was shown in Fig. 3. Based on the finding, it showed that tensile strength was increase as bio-phenolic loading increase from $5 \mathrm{wt} \%$ to $20 \mathrm{wt} \%$ and further increase in bio-phenolic loading to $25 \mathrm{wt} \%$ has shown a decline in tensile strength. A similar trend was shown regardless of the curing temperature used. The tensile strength of bio-phenolic/epoxy polymer blends was affected by the curing temperature. It was shown that increase in curing temperature from $100{ }^{\circ} \mathrm{C}$ to $150{ }^{\circ} \mathrm{C}$ has improved the tensile strength of bio-phenolic/epoxy polymer blend. The increasing trend was shown for all formulation. Improvement in tensile strength as curing temperature increase was due to the increase in the degree of cross-linking. Many factors will affect the strength of the polymer such as molecular weight, crosslinking, and crystallinity. An increase in the degree of crosslinking will provide additional bonds between molecules and increase the network formation. As a result, more load is required to break the 
bonds which lead to increase in tensile strength. Meanwhile, the investigation on tensile strength by Peng \& Zeng [18] on the performance of the phenolic with $5 \%$ mix epoxy resin systems has recorded that the tensile strength with value $20 \mathrm{MPa}$.

Besides that, lower tensile strength at $100{ }^{\circ} \mathrm{C}$ and $130{ }^{\circ} \mathrm{C}$ compared to $150{ }^{\circ} \mathrm{C}$ curing temperature might be due to the bio-phenolic/epoxy polymer blends do not fully cure at this temperature. Epoxy resin can be cured at room temperature with post-curing or applied heat using a hot press to increase the curing rate. This method is used by most researchers for epoxy resin. However, to cured phenolic resin used in this study, heat is needed and about $150{ }^{\circ} \mathrm{C}$. The curing temperature was important since if it is too low, the phenolic resin will not fully be cured. The nature of phenolic resin used in this study which needs a high curing temperature has affected the curing temperature of bio-phenolic/epoxy polymer blends. Therefore, the right curing temperature is needed to fabricate a fully cured polymer. A fully cured polymer will have better strength because most of the molecules are crosslinked and more energy needs to break the bonds.

\subsection{Tensile modulus}

The tensile modulus of different loading bio-phenolic/epoxy polymer blends with different curing temperatures was shown in Fig. 4. Based on Fig. 4 it is shown that the tensile modulus of biophenolic/epoxy polymer blends at $100{ }^{\circ} \mathrm{C}$ curing temperature was increased gradually as bio-phenolic loading increase. Increasing in tensile modulus with increase in bio-phenolic loading was due to the properties of phenolic which have higher tensile modulus compared to epoxy [27]. A similar trend was shown for curing temperatures at $130^{\circ} \mathrm{C}$ and $150^{\circ} \mathrm{C}$. When comparisons for each formulation were made, it was shown that increase in curing temperature has a negative effect on the tensile modulus of bio-phenolic/epoxy polymer blends. The tensile modulus showed decreasing trend as curing temperature increase from $100{ }^{\circ} \mathrm{C}$ to $150{ }^{\circ} \mathrm{C}$.

\subsection{Flexural strength}

The flexural strength of bio-phenolic/epoxy polymer blends with various bio-phenolic loading and curing temperature were shown in Fig. 5. Curing temperature affects the flexural strength of bio-phenolic/epoxy polymer blends. At $100{ }^{\circ} \mathrm{C}$ and $150{ }^{\circ} \mathrm{C}$ curing temperature, it was shown that flexural strength was increase as bio-phenolic loading increase from $5 \mathrm{wt} \%$ to $20 \mathrm{wt} \%$ and a further increase in bio-phenolic loading showed a slight decrease in flexural strength. It was shown that at $100{ }^{\circ} \mathrm{C}$ and $150{ }^{\circ} \mathrm{C}$ curing temperature the highest flexural strength was shown by $\mathrm{P}-20$ which is $82.6 \mathrm{MPa}$ and $119.8 \mathrm{MPa}$ respectively.

A different trend was shown for $130{ }^{\circ} \mathrm{C}$ curing temperature, where flexural strength was increase when bio-phenolic loading increase from $5 \mathrm{wt} \%$ to $10 \mathrm{wt} \%$. However, a further increase in bio-phenolic loading has a negative impact on flexural strength. The flexural strength gradually decreases with increase in biophenolic loading. It was shown that at $130{ }^{\circ} \mathrm{C}$ curing temperature the optimum loading of bio-phenolic is $10 \mathrm{wt} \%$ (P-10) which $109 \mathrm{MPa}$. When comparisons were made for each formulation, it was shown that 
increasing the curing temperature will improve the flexural strength of bio-phenolic/epoxy polymer blends. The study by Hiremath et al [24] on the effect of post-curing temperature of epoxy/alumina polymer nanocomposite has indicated that the post-curing at a temperature below the glass transition temperature of epoxy enhanced on flexural properties. Increase in flexural strength is due to the increase in degree of crosslinking when polymer undergoes post-curing. Lascano et al [28] found that increase the curing temperature of bio-based epoxy from $70{ }^{\circ} \mathrm{C}$ to $90^{\circ} \mathrm{C}$ has improved the flexural strength from 77.4MPa to $105.6 \mathrm{MPa}$. Increase in flexural strength when curing temperature increase was due to the increase in crosslinking between molecules which increased network structure, thus the polymer can withstand more load during the flexural test, and it showed higher flexural strength. Formation of network structure will improve the flexural strength [16,29].

\subsection{Flexural modulus}

The effect of bio-phenolic loading and curing temperature on the flexural modulus of bio-phenolic/epoxy polymer blends were shown in Fig. 6 . At $100{ }^{\circ} \mathrm{C}$ curing temperature addition of bio-phenolic from $5 \mathrm{wt} \%$ to $10 \mathrm{wt} \%$ has improved the flexural modulus of bio-phenolic/epoxy polymer blend. However, a slightly decrease in flexural modulus as bio-phenolic was increased to $15 \mathrm{wt} \%$. Further increase in bio-phenolic to $20 \mathrm{wt} \%$ and $25 \mathrm{wt} \%$ seem to have improved the flexural modulus and it has compared with the flexural modulus which showed by P-10. The highest flexural modulus for $100{ }^{\circ} \mathrm{C}$ curing temperature was shown by bio-phenolic/epoxy polymer blends with $25 \mathrm{wt} \%$ bio-phenolic which $4.2 \mathrm{GPa}$. A different trend was shown for bio-phenolic/epoxy polymer blends cured at $130{ }^{\circ} \mathrm{C}$ curing temperature. Increase in biophenolic loading from $5 \mathrm{wt} \%$ to $10 \mathrm{wt} \%$ has improved the flexural modulus. Nevertheless, further addition of phenolic resin up to $20 \mathrm{wt} \%$ does not have a significant difference in flexural modulus. The addition of bio-phenolic resin to $25 \mathrm{wt} \%$ has again improved the flexural modulus of bio-phenolic/epoxy polymer blend and this is the highest flexural modulus for blend cured at $130{ }^{\circ} \mathrm{C}$ which $4.5 \mathrm{GPa}$. A similar trend was shown for bio-phenolic/epoxy polymer blends cured at $150{ }^{\circ} \mathrm{C}$ with bio-phenolic/epoxy polymer blends cured at $100{ }^{\circ} \mathrm{C}$. When comparisons for each formulation are made, it was shown that an increase in curing temperature has from $100{ }^{\circ} \mathrm{C}$ to $130^{\circ} \mathrm{C}$ has improved the flexural modulus. However, continue to increase the curing temperature from $130{ }^{\circ} \mathrm{C}$ to $150{ }^{\circ} \mathrm{C}$ has a negative impact on the flexural modulus of bio-phenolic/epoxy polymer blends. Bio-phenolic/epoxy polymer blends cured at $150{ }^{\circ} \mathrm{C}$ has the lowest flexural modulus for most of the formulation except for P- 5 which curing $100{ }^{\circ} \mathrm{C}$ has almost similar flexural modulus compared to cured at $150^{\circ} \mathrm{C}$.

\subsection{Impact Strength}

Impact strength is important in most applications because the ability of structures to withstand repeated impacts is critical to the design's robustness, particularly in the transportation and consumer goods industries. As a result, the ability of structures, especially in the transportation and consumer goods industries, to withstand repeated impacts is critical to the robustness of the construction, according to numerous studies of polymer blend effect on impact tolerance [30-32] The behaviour of advanced materials suitable for impact resistance was developed and studied by material researchers and 
designers, therefore, eco-friendly and biodegradability are the most favoured requirements of making green composites, however natural fibers, biopolymers and bio-fillers could be utilised as sustainable additives for manufacturing biodegradable products [33,34] From numerous bioresources, a number of epoxy thermosets have been synthesized and the challenges and opportunities in developing sustainable epoxy thermosets and materials from bio-based monomeric phenols are presented in various results of mechanical properties such as impact resistance and flame-retarding ability $[34,35]$

Therefore, in the impact resistance of bio-phenolic/epoxy polymer blends were shown in Fig. 7 has resulted the impact resistance was gradually increased as bio-phenolic loading increase from $5 \mathrm{wt} \%$ to 20 $w t \%$. However, the addition of $25 \mathrm{wt} \%$ of bio-phenolic has slightly decreased the impact resistance of biophenolic epoxy polymer blends. Regardless of the curing temperature used, a similar trend was shown. The effect of curing temperature for each formulation was studied. It is shown that the impact resistance of bio-phenolic/epoxy polymer blends for $5 \mathrm{wt} \%$ bio-phenolic was decreased as curing temperature increase. The decrease in impact resistance was due to the weak interaction between epoxy and phenolic at lower bio-phenolic loading. However, other formulation showed a different trend compared to P-5. Increase curing temperature has improved the impact resistance of bio-phenolic/epoxy polymer blends. Increase in impact strength was due to the increase in the degree of crosslinking and network formation between epoxy and bio-phenolic molecules. The higher degree of crosslinking and network formation will help the material to generate a plastic deformation zone which helps the material to absorb more energy during impact as a result the impact resistance improved [36,37]

\section{Conclusion}

The properties of polymer blends were depending on various factors such as the ratio of polymer and curing temperature. This study has shown that different loading of bio-phenolic and curing temperature will affect the mechanical properties of bio-phenolic/epoxy polymer blends. The tensile strength and flexural strength of bio-phenolic/epoxy polymer blends were improved when the curing temperature increase. While tensile modulus has decreased with increasing curing temperature. A different trend was shown for flexural modulus where the highest flexural modulus was shown by bio-phenolic/epoxy polymer blends cured at $130{ }^{\circ} \mathrm{C}$. Interestingly, the impact resistance decreases at $5 \mathrm{wt} \%$ loading when curing temperature increases. However, other ratios of bio-phenolic/epoxy polymer blends showed increase in impact resistance as curing temperature increase. Based on the analysis its can be concluded that the mechanical properties of bio-phenolic/epoxy polymer blends are better at higher temperature which is $150^{\circ} \mathrm{C}$.

\section{Declarations}

\section{Acknowledgements}

The authors are thankful to the Ministry of Higher Education for supporting the research through HICOE grant: 6369108 and the authors are grateful to Universiti Putra Malaysia for the financial support of this 
research through Graduate Research Fellowship

\section{Conflicts of Interest}

The authors declare no conflict of interest.

\section{References}

[1] Brydson JA (1993) Plastic Material. $7^{\text {th }}$ ed, Elsevier Ltd, $7^{\text {th }}$ ed: pp. 635-667. https://doi.org/101016/B978-075064132-6/50064-4.

[2] Asim M, Saba N, Jawaid M, Nasir M, Pervaiz M., Alothman OY (2017) A review on Phenolic resin and its Composites. Curr Anal Chem 13 https://doi.org/10.2174/1573411013666171003154410.

[3] Asyadi F, Jawaid M, Hassan A, Wahit MU (2013) Mechanical Properties of Mica-Filled Polycarbonate/Poly(Acrylonitrile-Butadiene-Styrene) Composites. Polym Plast Technol Eng 52:727-736. https://doi.org/10.1080/03602559.2012.762672.

[4] Frollini E, Castellan (2012) A Phenolic Resins and Composites. Wiley Encycl Compos 1-10. https://doi.org/10.1002/9781118097298.weoc167.

[5] Allen DJ, Ishida H (2001) Thermosets: phenolics, novolacs, and benzoxazine. Encycl. Mater. Sci. Technol. Second Ed. 9226-9229. https://doi.org/10.1016/B0-08-043152-6/01662-4.

[6] Choi GG, Oh SJ, Lee SJ, Kim JS (2015) Production of bio-based phenolic resin and activated carbon from bio-oil and biochar derived from fast pyrolysis of palm kernel shells. Bioresour. Technol. 178:99107. https://doi.org/10.1016/j.biortech.2014.08.053.

[7] Sarika P.R., Nancarrow P, Khansaheb A, Ibrahim T (2020) Bio-based alternatives to phenol and formaldehyde for the production of resins. Polymers 12:1-24. https://doi.org/10.3390/polym12102237.

[8] Mouritz AP (2012) Polymers for aerospace structures, in: Introd to Aerosp Mater, Woodhead Publishing Limited,: pp. 268-302. https://doi.org/10.1533/9780857095152.268.

[9] Abdellaoui H, Raji M, Bouhfid R, el kacem Qaiss A (2019) Investigation of the deformation behavior of epoxy-based composite materials. in: M. Jawaid, M.T. Hameed Sultan, N. Saba (Eds.), Fail Anal Biocomposites, Fibre-Reinforced Compos. Hybrid Compos,: pp. 29-49. https://doi.org/10.1016/B978-008-102293-1.00002-4.

[10] Hodd K (1989) Epoxy resins. in: Compr Polym Sci Suppl, Elsevier,: pp. 667-699. https://doi.org/doi.org/10.1016/B978-0-08-096701-1.00178-6.

[11] Hua FJ, Hu CP (1999) Interpenetrating polymer networks of epoxy resin and urethane acrylate resin: 2. Morphology and mechanical property, Eur Polym J 36:27-33. https://doi.org/10.1016/S0014- 
3057(99)00027-0.

[12] Li J, Zhang J, Zhang S, Gao Q, Li J, Zhang W (2018) Alkali lignin depolymerization under ecofriendly and cost-effective $\mathrm{NaOH} /$ urea aqueous solution for fast curing bio-based phenolic resin. Ind Crops Prod 120:25-33. https://doi.org/10.1016/j.indcrop.2018.04.027.

[13] Benyahya S, Aouf C, Caillol S, Boutevi B, Pascault JP, Fulcrand H (2014) Functionalized green tea tannins as phenolic prepolymers for bio-based epoxy resins. Ind Crops Prod 53:296-307. https://doi.org/10.1016/j.indcrop.2013.12.045.

[14] Cardona F, Aravinthan T, Fedrigo J, Moscou C (2010) Synthesis of phenolic bio-resins for advanced composites in civil engineering structures. In Proceedings of the Southern Region Engineering Conference (SREC 2010) (pp. 58-64). Engineers Australia.

[15] Ciesielski M, Burk B, Heinzmann C, Döring M (2017) Fire-retardant high-performance epoxy-based materials. Elsevier Ltd,. https://doi.org/10.1016/b978-0-08-100136-3.00002-9.

[16] Mahesh KPO, Alagar M, Ananda Kumar S (2003) Mechanical, thermal and morphological behavior of bismaleimide modified polyurethane-epoxy IPN matrices. Polym Adv Technol 14:137-146. https://doi.org/10.1002/pat.341.

[17] Unnikrishnan KP, Thachil ET (2006) Hybrid polymer networks of epoxy resin and substituted phenolic novolacs. Int J Polym Mater Polym Biomater 55:563-576.

https://doi.org/10.1080/00914030500236833.

[18] Peng YL, Zeng L (2015) Study on the Phenolic - Epoxy Resin System. Adv Mater Res 1088:439443. https://doi.org/10.4028/www.scientific.net/amr.1088.439.

[19] Parameswaranpillai J, Thomas S, Grohens Y (2015) Polymer Blends: State of the Art, New Challenges, and Opportunities, in: Charact. Polym. Blends Miscibility, Morphol. Interfaces,: pp. 1-6. https://doi.org/10.1002/9783527645602.ch01.

[20] Qin Y (2016) Applications of advanced technologies in the development of functional medical textile materials. in: Med. Text. Mater., Woodhead Publishing,: pp. 55-70.

https://doi.org/doi.org/10.1016/B978-0-08-100618-4.00005-4.

[21] Niaounakis M (2015) Blending. in: Biopolym. Process. Prod., Elsevier,: pp. 117-185. https://doi.org/doi.org/10.1016/B978-0-323-26698-7.00003-9.

[22] Rohde BJ, Le KM, Krishnamoorti R, Robertson ML (2016) Thermoset Blends of an Epoxy Resin and Polydicyclopentadiene. Macromolecules. 49:8960-8970.

https://doi.org/10.1021/acs.macromol.6b01649. 
[23] Sultan SR, Salah NJ, Razak AAA (2008) Improve the Performance of Epoxy Resin and Poly (Vinyl Butyral) As an Aluminum Metal Adhesion. J Technique. 23(1):35-45.

[24] Hiremath V, Singh M, Kumar D (2014) Effect of Post Curing Temperature on Viscoelastic and Flexural Properties of Epoxy / Alumina Polymer Nanocomposites. Procedia Eng 97:479-487. https://doi.org/10.1016/j.proeng.2014.12.272.

[25] Zareanshahraki F, Jannesari A, Rastegar S (2020) Morphology , optical properties, and curing behavior of UV-curable acrylate-siloxane polymer blends. Polym Test 85: 106412. https://doi.org/10.1016/j.polymertesting.2020.106412.

[26] Motawie AM, Badr MM, Amer MS, Moustafa HY, Ali IM (2008) Some Coating Studies on Phenolic Epoxy / Poly(Vinyl Acetal) Resins. J Appl Sci Res 4:1043-1051.

[27] Ismail AS, Jawaid M, Hamid NH, Yahaya R, Hassan A (2021) Mechanical and Morphological Properties of Bio-Phenolic/Epoxy Polymer Blends. Molecules 26:773.

https://doi.org/10.3390/molecules26040773.

[28] Lascano D, Quiles-Carrillo L, Torres-Giner S, Boronat T, Montanes N (2019) Optimization of the curing and post-curing conditions for the manufacturing of partially bio-based epoxy resins with improved toughness. Polymers,. 11(8):1354.

[29] Hsieh KH, Chiang YC, Chern YC, Chiu WY, Ma CCM (1991) Interpenetrating polymer networks of polyurethanes and epoxy resin, I. Mechanical behavior. Die Angew Makromol Chemie 193:89-98. https://doi.org/10.1002/apmc.1991.051930109.

[30] Supian ABM, Sapuan SM, Zuhri MYM, Zainudin ES, Ya HH, Hisham HN (2021) Effect of winding orientation on energy absorption and failure modes of filament wound kenaf/glass fibre reinforced epoxy hybrid composite tubes under intermediate-velocity impact (IVI) load. J Mater Res Technol 10:1-14. https://doi.org/10.1016/j.jmrt.2020.11.103.

[31] Viratyaporn W, Lehman RL, Joshi J (2007) Impact resistance of selected immiscible polymer blends. Annu Tech Conf - ANTEC, Conf Proc 3:1843-1847.

[32] Jin FL, Park SJ (2008) Impact-strength improvement of epoxy resins reinforced with a biodegradable polymer. Mater Sci Eng A 478:402-405. https://doi.org/10.1016/j.msea.2007.05.053.

[33] Clifton S, Thimmappa BHS, Selvam R, Shivamurthy B (2020) Polymer nanocomposites for highvelocity impact applications-A review. Compos Commun 17:72-86. https://doi.org/10.1016/j.coco.2019.11.013.

[34] Wan J, Zhao J, Zhang X, Fan H, Zhang J, Hu D, Jin P, Wang DY (2020) Epoxy thermosets and materials derived from bio-based monomeric phenols: Transformations and performances. Prog Polym Sci 108:101287. https://doi.org/10.1016/j.progpolymsci.2020.101287. 
[35] Zhang J, Mi X, Chen S, Xu Z, Zhang D, Miao M, Wang J (2020) A bio-based hyperbranched flame retardant for epoxy resins. Chem Eng J 381:122719. https://doi.org/10.1016/j.cej.2019.122719.

[36] Zhang N, Zeng C, Wang L, Ren J (2013) Preparation and Properties of Biodegradable Poly(lactic acid)/Poly (butylene adipate-co-terephthalate) Blend with Epoxy-Functional Styrene Acrylic Copolymer as Reactive Agent. J Polym Environ 21:286-292. https://doi.org/10.1007/s10924-012-0448-z.

[37] Ojijo V, Sinha Ray S, Sadiku R (2013) Toughening of biodegradable polylactide/poly(butylene succinate- co -adipate) blends via in situ reactive compatibilization. ACS Appl Mater Interfaces 5:42664276. https://doi.org/10.1021/am400482f.

\section{Table}

Table 1: Formulation and label of each sample

\begin{tabular}{|lll|}
\hline Label & Phenolic resin (wt\%) & Epoxy resin (wt\%) \\
\hline E & 0 & 100 \\
\hline P-5 & 5 & 95 \\
\hline P-10 & 10 & 90 \\
\hline P-15 & 15 & 85 \\
\hline P-20 & 20 & 80 \\
\hline P-25 & 25 & 75 \\
\hline P & 100 & 0 \\
\hline
\end{tabular}

\section{Figures}



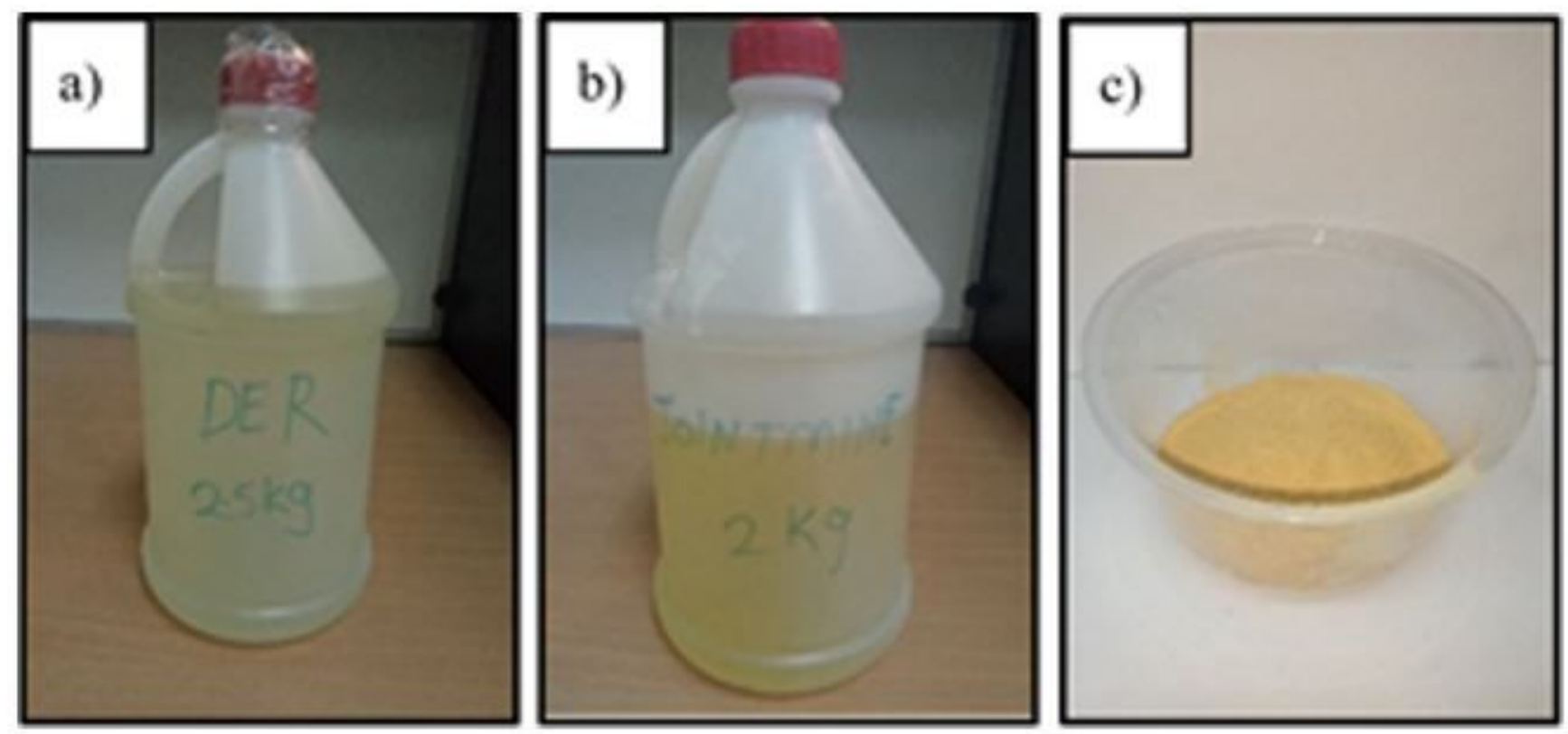

Figure 1

(a) Epoxy Resin (b) Epoxy Hardener (c) Phenolic Resin

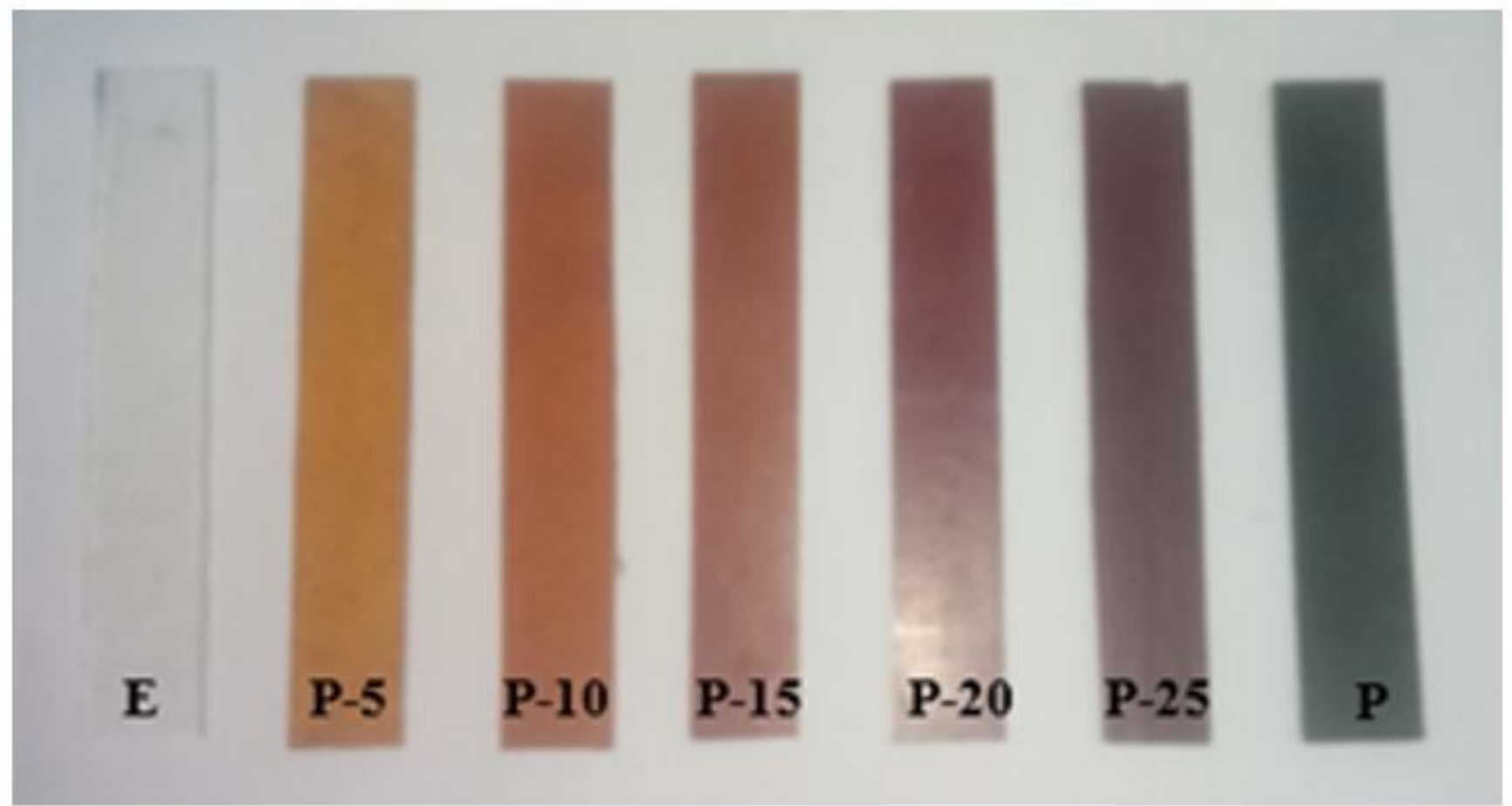

Figure 2

Prepared Sample 


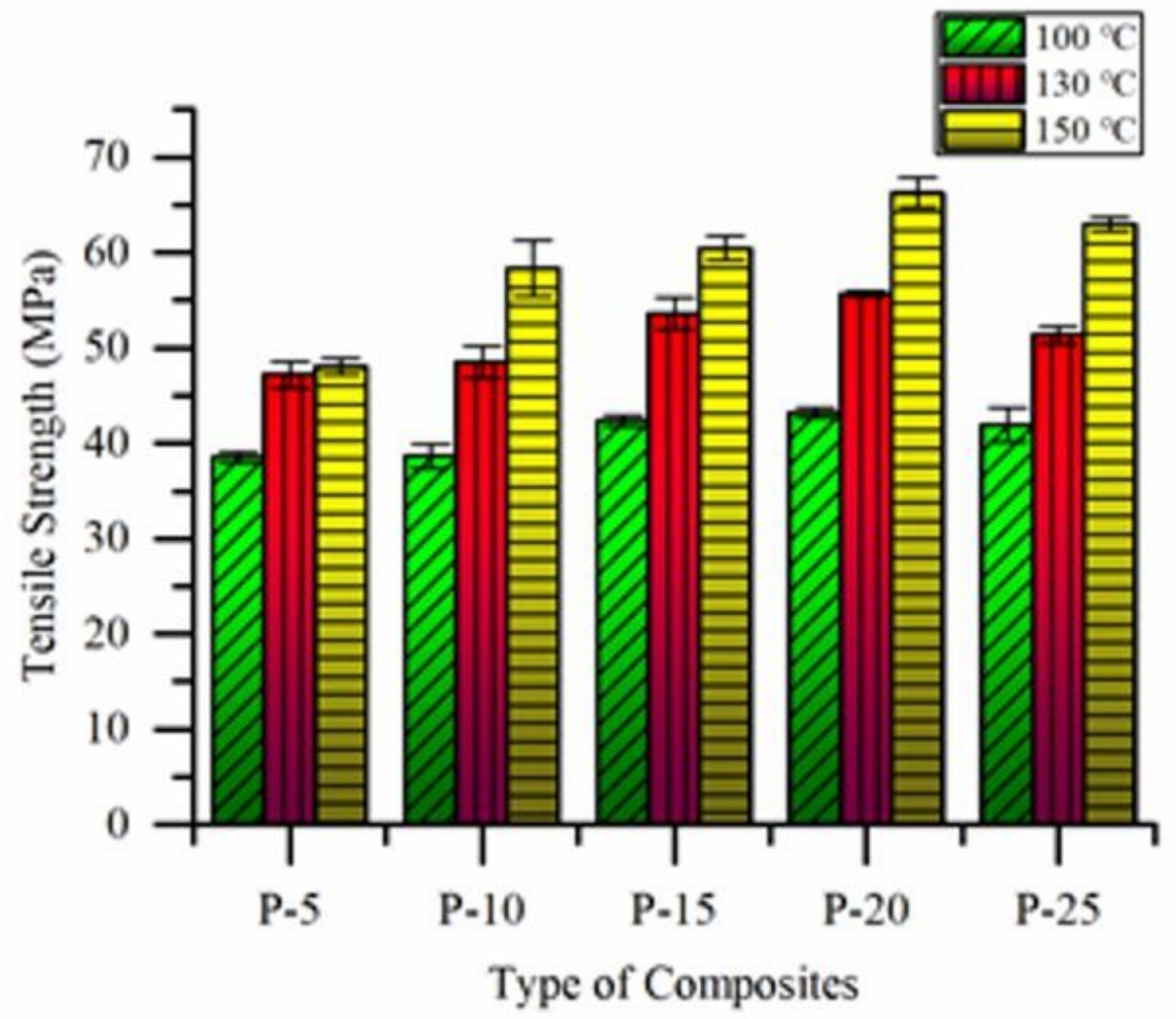

Figure 3

Tensile strength of bio-phenolic/epoxy blends composite 


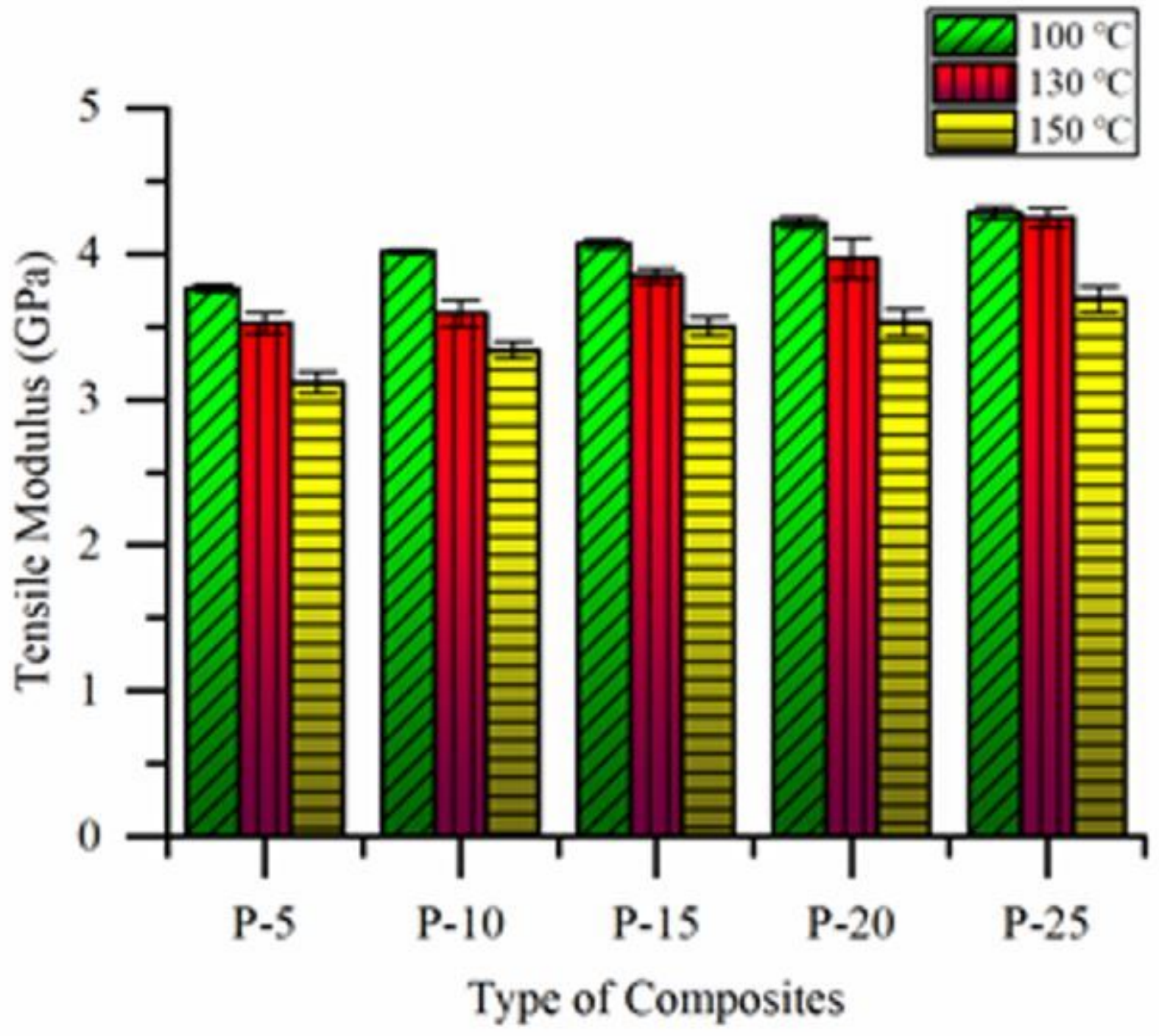

Figure 4

Tensile modulus of bio-phenolic/epoxy blends composites 


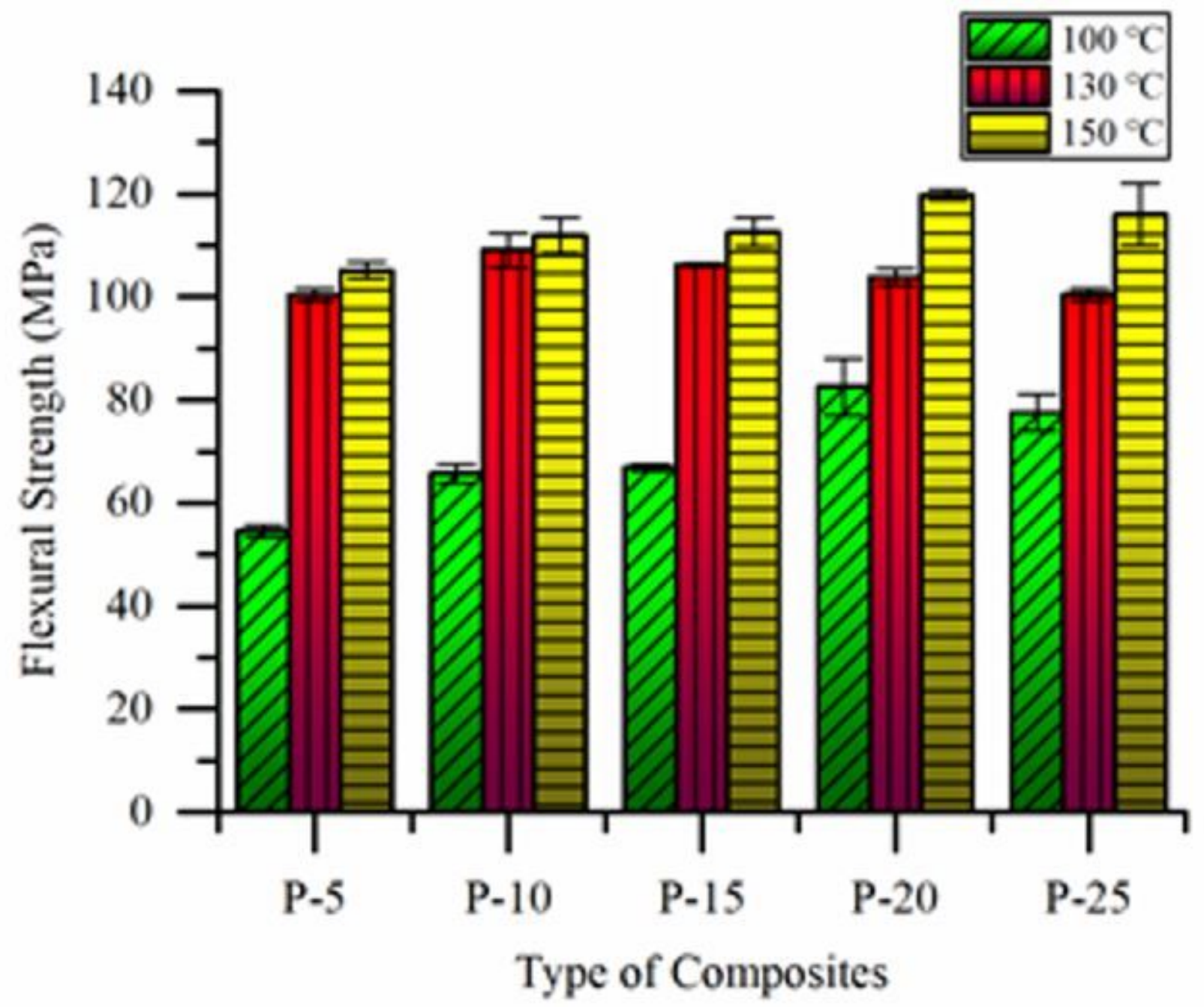

Figure 5

Flexural strength of bio-phenolic/epoxy blends composites 


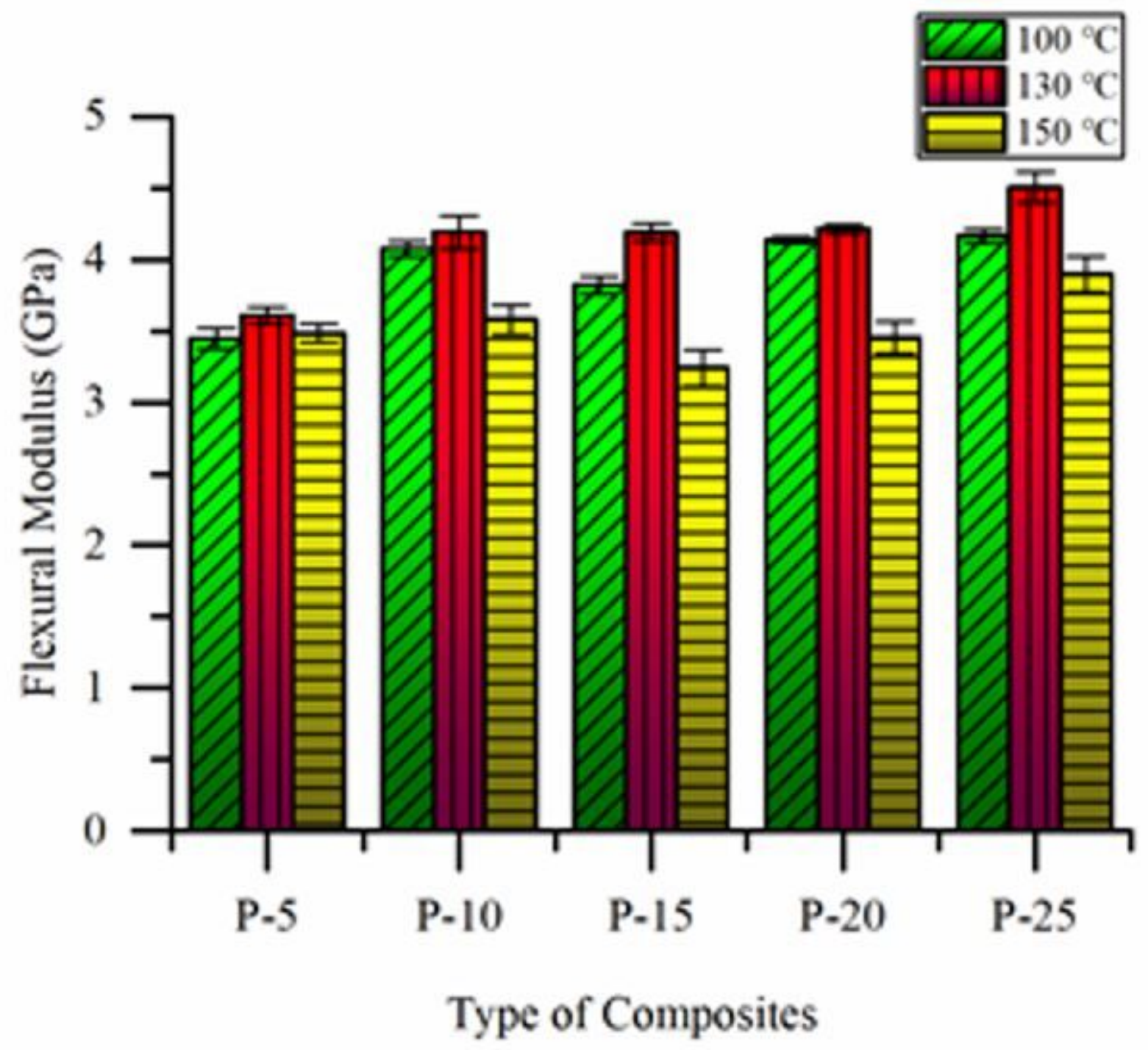

Figure 6

Flexural modulus of bio-phenolic/epoxy blends composites 


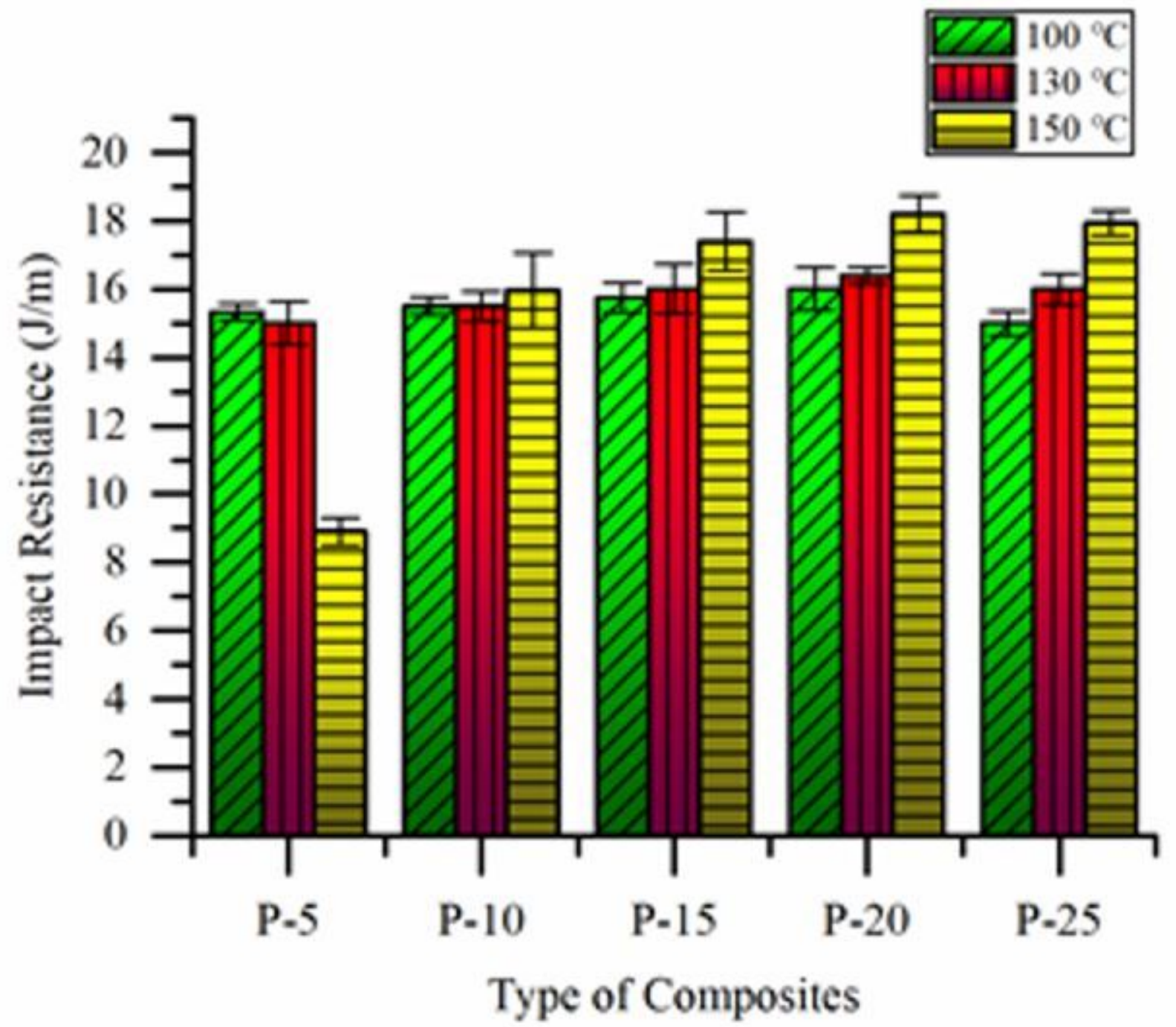

Figure 7

Impact resistance of bio-phenolic/epoxy blends composites

\section{Supplementary Files}

This is a list of supplementary files associated with this preprint. Click to download.

- formula.docx 